\title{
Relevance of Emoticons in Computer-Mediated Communication Contexts: An Overview
}

\author{
Tanimu Ahmed Jibril ${ }^{1} \&$ Mardziah Hayati Abdullah ${ }^{1}$ \\ ${ }^{1}$ Department of English, Faculty of Modern Languages \& Communication, Universiti Putra Malaysia, Serdang, \\ Malaysia
}

Correspondence: Tanimu Ahmed Jibril, Block B-2-035-1B, Jalan LP 7/2, Lestari Perdana, Bandar Putra Permai, 43300 Selangor, Darul Ehsan, Malaysia. Tel: 60-14-648-1694. E-mail: ahmedtanimu76@gmail.com

Received: December 19, 2012 Accepted: January 29, 2013 Online Published: March 28, 2013

doi:10.5539/ass.v9n4p201

URL: http://dx.doi.org/10.5539/ass.v9n4p201

\begin{abstract}
With the constant growth in Information and Communication Technology (ICT) in the last 50 years or so, electronic communication has become part of the present day system of living. Equally, smileys or emoticons were innovated in 1982, and today the genre has attained a substantial patronage in various aspects of computer-mediated communication (CMC). Ever since written forms of electronic communication lack the face-to-face (F2F) situation attributes, emoticons are seen as socio-emotional suppliers to the CMC. This article reviews scholarly research in that field in order to compile variety of investigations on the application of emoticons in some facets of CMC, i.e. Facebook, Instant Messaging (IM), and Short Messaging Service (SMS). Key findings of the review show that emoticons do not just serve as paralanguage elements rather they are compared to word morphemes with distinctive significative functions. In other words, they are morpheme-like units and could be derivational, inflectional, or abbreviations but not unbound. The findings also indicate that emoticons could be conventionalized as well as being paralinguistic elements, therefore, they should be approached as contributory to conversation itself not mere compensatory to language.
\end{abstract}

Keywords: information technology, smileys, computer-mediated communication, relevance of emoticons

\section{Introduction}

It has become evident that process of communication is complex as such that it goes beyond plain speaking, writing and words interpretation. Components such as language and its content, grammar, expertise and non-verbal cues are also involved (Rezabek \& Cochenour, 1998). Non-verbal type of communication is represented in conveying messages through some non-words rudiments. Forms of non-verbal interactions include gestures, eye contacts, facial expressions, body language, etc. Dancing, mode of dresses, architecture, paintings and sculptures also convey meanings, and are all regarded as part of the non-verbal attributes. The main feature of non-verbal cues is its "ability to convey emotions and attitude" as well as "emphasize, contradict, substitute or regulate verbal communication" (Wei, 2012, pp. 2-3). Emoticons are considered to be socio-emotional suppliers in the computer-mediated communication (CMC) and, particularly, in Short Messaging Service (SMS) context (Riva, 2002). Contrary to F2F communication, CMC is written-based and it lacks most of non-verbal elements, therefore, emoticons were incorporated to enable a receiver understand the feeling or mood of a given sender by way of these cues (Wei, 2012). Moreover, a study shows that "in text-based virtual interactions", emoticons provide participants with some of the richness of real-time, face-to-face interactions. Emoticons were described as "iconic forms" that "had made their way" into the written-based CMC to "indicate the writer's mood or feeling" (Gajadhar \& Green, 2005; Innocent, 2001; Wei, 2012, p. 12).

\section{Defining Emoticons}

By way of description, Danesi (2009) explains that emoticons, as a form of computer-mediated communication $(\mathrm{CMC})$ are:

String of keyboard characters that, when viewed sideways (or in some other orientation), can be seen to suggest a face expressing a particular emotion. An emoticon is often used in an e-mail message or newsgroup posting as a comment on the text that accompanies it. Common emoticons include the smiley :-) or :) and the 
winkey ;-) and the yawn :-O, among others (p. 110).

Emoticons are referred to as "rational icons" by Asteroff (1987) as cited in Walther and D'Addario (2001, p. 326). The application of emoticons in electronic mails was documented in a case study research (Asteroff, 1987). Thompson and Foulger (1996) tagged them as "pictographs" and consider their use in CMC as a way to show emotion or "as surrogates for nonverbal communication" (p. 226). In the same vein, emoticons are described as a chain of orndinary inscription one can come across on a computer keyboard. They are applied in various aspects of communication through computers (Sanderson, 1993). It has been assumed that "until the advent of the smiley, otherwise known as an emoticon, individuals using electronic communication had no way to indicate the subtle mood changes. They couldn't tell jokes, use irony, slip in a pun or become bitingly sarcastic" (Godin, 1993, p. 4). In another perception, emoticons have been seen as "icons for the expression of emotion, or for marking one's intent as non-serious". It has also been argued that CMC itself has developed "from a work-related medium to a playful medium", therefore, a room has been given for "the continued development and use of emoticons". (Danet, Reudenberg-Wright, \& Rosenbaum-Tamari, 1997; Walther \& D’Addario, 2001, p. 326). According to Luor, Lu, Wu, and Tao (2010), emoticons could be characterized as "a creative and visually salient way to add expression to an otherwise strictly text-based form". Since their meanings represents emotion, therefore, "their actual function hinges on the definition of the word emotion" (p. 890).

A number of research studies have signified the importance of nonverbal codes in comprehending "the meaning and nature of the message in F2F" (Argyle, 1988, in Tossell, Kortum, Shepard, Barg-Walkow, \& Rahmati, 2012, p. 659). A communication theory such as Social Presence Theory (SPT), for instance, has suggested that Computer-Mediated Communication (CMC) is short of "contextual information" and that "the medium is disruptive for understanding the content and nature of messages" (Sproull \& Liesler, 1986; Walther, 1992; Tossell et al., 2012, p. 659). On the other hand, later research studies have indicated that emoticons are capable of providing such information and improving the CMC (Derks, Fischer, \& Bos, 2008). Therefore, emoticons have turned out to be socioemotional suppliers in messages context, as well as the most important way of conveying emotions in CMC (Riva, 2002). By way of explanation, emoticons are considered to be "visual cues formed from ordinary typographical symbols that when read sideways represent feelings or emotions". It is obvious that electronic communication does away with most of the visual cues found in face-to-face interactions. As result of that, emoticons are incorporated "as visual cues to augment the meaning of textual messages" (Rezabeck \& Cochenour, 1998, p. 201). That is to say, emoticons were subsequently introduced into the cyberspace to substitute the absence of gestures and facial attributes in electronic forms of communication.

In another account, the Hacker's Dictionary codes emoticons as "an ASCII glyph" that "is used to indicate an emotional state in e-mail or news" (Raymond, 1994; Amaghlobeli, 2012, p. 348). Moreover, emoticons as smileys are described the same as series of commonplace lettering found on a computer keyboard. They are functional in e-mails and other varieties of communication by the use of computers (Sanderson, 1993, in Amaghlobeli, 2012). On the other end of Sanderson's (1993) assertion, emoticons are classified as a sort of "creativity" that "manifests itself" in the sense that text message writers manipulate the ASCII letters of the mobile phones to design "pictures, symbols and icons...." (Taiwo, 2010, p. 14). In corroboration with the view of Rezabek and Cochenour (1998) above, Godin (1993) adds that, prior to the introduction of smileys people communicating electronically had no channels to demonstrate changes in their moods, let alone telling jokes, sarcasm or using irony. To sum it up, emoticons are classified as the paralanguage of the internet (Marvin, 1995).

It is widely believed that Scott Fahlman, of Carnegie Melon School of Computer Science, formulated the first smiley face composed of a smiling mouth, eyes and a nose in 1982 (Lang, 2009). Although, Wei (2012) states that "the origin of emoticons can be traced to as far back as 1967" as the first version of emoticon featured in an article of Reader's Digest. Therefore, Fahlman is regarded as the inventor for the fact that he proposed its application (p. 3). This innovation started as text based and, progressively, developed into graphical emoticons. At the moment, Microsoft Word and other programmes mechanically convert text based emoticons into graphic ones, which turned out to be more expressive, mostly animated in Gif configuration (Amaghlobeli, 2012). Investigations into emoticons were carried out from variety of standpoints focusing on a number of objectives. For instance, emoticons analysed as politeness marker (Bunz \& Campbell, 2004). In psychology, some research was based on the emotional aspect of emoticons and the role it plays in message understanding (Walther $\&$ D’Addario, 2001). Moreover, Bodi and Veszelszki (2006) conducted a linguistic study of emoticons where their semantic and syntactic descriptions were analysed. Likewise, the visual segments of emoticons were investigated by Herring (2001), as cited in Amaghlobeli (2012). 


\section{Impacts of Emoticons on Message Interpretation}

Psychologist Albert Mehrabian believes that $93 \%$ of human communication takes place non-verbally. According to a research conducted at $3 \mathrm{M}$ Corporation, human brain processes visual elements 60,000 times faster that written texts. That is to say, human brain decrypts image elements in an instantaneous method, while language is decoded in a linear, chronological manner requiring extra time to process (Parkinson, 2007).

Emoticons were basically invented to enhance humour and likewise to alleviate undesirable connotation in text messages (Wolf, 2000). Studies conducted on the roles of emoticons in textual communication indicate that emoticons are capable of strengthening the effect of an unwritten message, emphasize a meaning throughout the creation and interpretation of a given message, and equally simplify written messages (Walther \& D'Addario, 2001; Crystal, 2001; Reabeck \& Cochenour, 1998; Braumann, Preveden, Saleem, Xu \& Koeszegi, 2010). In line with this supposition, it has been suggested that emoticons carry out parallel functions the way non-verbals do in F2F (Braumann et al., 2010). In other words, they function as clarifiers in textual communication which is comparable to what nonverbals demonstrate in F2F (Derks et al., 2008; Walther \& D'Addario, 2001). Moreover, emoticons are believed to "communiacate more clearly a current mood or mental state of the author, thereby also providing additional social cues about this person" (Costantin, Kalyanaraman, Stavrositu, \& Wagoner, 2002; Thompson \& Foulger, 1996; Luor et al., 2010, p. 893).

In a study carried out to investigate the non-verbal communication functions of emoticons in CMC, Lo (2008) concluded that frequently when Internet users come across texts without emoticons, they find it difficult to perceive the precise emotion and the attitude expressed. On the other hand, using visual cues combined with the text gives an added positive attitude than text only (Mitchell, 1986). Walther and D'Addario (2001) examined the impacts of emoticons on message interpretation in CMC. The study was based on an experiment of 3 common emoticons on message understanding. The outcome of the study shows that emoticons' influences were surpassed by verbal content. The results indicate that any negative element in a message, be it verbal or graphic, will move the message understanding to that negative element. In their own opinion, Derks et al. (2008) see that emoticons do affect online communication understanding. They argue that "positive message with a smile is rated more positively than a positive pure message, and a negative message with a supporting frown is more negative than a negative pure message". Though, they believe that "the emoticon do not have the strength to turn around the valence of the verbal message" (Derks et al., 2008; Luor et al., 2010, p. 894).

In another account, Ip (2002) carried out an experiment to compare and find out the effects of both emoticons and 2 grammatical markers (i.e. use of punctuation and exclamation marks) in terms of understanding IM text messages either positively or negatively. Results of the study indicated that emoticons appeared to have increased the valence of messages and made them much more extreme. The findings also suggested that emoticons have higher impacts on messages in the absence of any exclamation mark. On the other hand, exclamation marks make negative messages more negative but do not have any impacts in the presence of emoticons. It has also become evident that emoticons and punctuation marks have tremendous effects on how people perceive and interpret messages. The study concluded that as much as the way emoticons make messages appear emotionally intense, likewise, a number of exclamation marks make positive messages look like more positive.

Braumann et al. (2010) conducted a laboratory experiment to test the effects of six different emoticons on a communication seesion, and also to see the outcomes of synchronous and asynchronous electronic negotiations. An e-communication support system was designed to enable participants manipulate messages. It can be used asynchronously or synchronously and it allows two treatments when it comes to the use of emoticons. The results show how tremendous was the effects of emoticon treatment and the communication approach on the behavior of the negotiation. In synchronous negotiations where participants were forced to use emoticons, the use of competitive behavior with more refusals and not as much of compliant communication was high. On the contrary, in asynchronous negotiations where participants were not forced to use emoticons, the information behavior was further competitive and the participants used more persuasive opinions.

Luor et al.'s (2010) study explored the likely effects of emoticons in place of work. Findings of the study indicate that, in some situations, IMs with emoticons did succeed in generating different emotional outcomes than IMs lacking emoticons. That is to say, emoticons may function as altered text messages. In a cross-gender examination, Wolf (2000) realized that in a discussion among the two genders, use of emoticons by men rose to almost the same level with women's. Nevertheless, she concluded that women use emoticon for humour rather than ridicule, while men use it for ridicule more than humaour. 


\section{Emoticons and Computer-Mediated Communication}

Emoticons have become "widely known" and "commonly recognized among CMC users". They are regarded as "substituting for the nonverbal cues" (Luor et al., 2010, pp. 894-5). It has been posited that "computer-mediated communication (CMC) replaces some face-to-face interaction", therefore, "the nature of communication has changed" (Huang, Yen, \& Zhang, 2008, p. 467). Emoticons are expected to substitute the missing human and emotional touches in electronic communication as written texts are completely "divorced from gestures, facial expressions, and prosodic features..." (Amaghlobeli, 2012, p. 348). Rezabeck and Cochenour (1998) state that "because the use of e-mail eliminates visual cues such as head nodding, facial expressions, posture, and eye contact fond in face-to-face communication, CMC users often incorporate emoticons as visual cues to augment the meaning of textual electronic messages" (pp. 201-202).

A number of research works approached the use of emoticons in CMC with different references. For example, Wei (2012) has examined the use of emoticons in Facebook. The researcher sought to understand the possibility of infusing text-based CMC on Facebook with the same level of richness and authenticity of F2F communications. She also wanted to understand how different groups use emoticons. Garrison et al. (2011) conducted an investigation to examine emoticons as conventions of Instant Messaging (IM) discourse. Likewise, Huang et al. (2008) studied emoticons with reference to IM too. A longitudinal survey was carried out by Tossell et al. (2012) in order to figure out how emoticons are used in text messages and to understand the differences among genders when it comes to frequency of usage. The linguistic components of typographic emoticons in SMS language have been investigated (Amaghlobeli, 2012).

In a research corpus that covered 258 French text messages gathered through questionnaires between 2008 and 2009, Amaghlobeli (2012) conducted a graphic analysis of emoticons contained in the text messages collected. The study was designed to investigate linguistic properties in the main three types of emoticons that are found in electronic communication, to be precise, typographic, graphic and verbal emoticons. The overall findings suggest that two main types of emoticons use have been identified, verbal and non-verbal. It also shows that "emoticons are not only paraverbal devices but also structural markers and play significant role in the formation of sentences" (p. 353).

A further survey was carried out by Huang et al. (2008) to explore the potential effects of emoticons. This time around the researchers sampled some 216 college students in Midwestern United States who use Instant Messaging (IM) and used custom-designed instrument for the study. The model applied was to look at affiliations among emoticons use, perceive usefulness, information richness, personal interaction, and enjoyment. The outcome indicates that emoticons have a direct effect on enjoyment, while enjoyment has an effect on personal interaction as well. Though students were sampled for the study, but from all indications, the results have an implication beyond the sampled population for the fact that the students would eventually join the labour force. That is to say, the outcome is of benefits to business organizations too.

A longitudinal survey has been carried out to understand the use of emoticons in text messages, differences between genders and the frequency of the usage through smartphones. Tossell et al. (2012) sampled some 21 students, from diverse academic specializations, to participate in a quasi-experimental method that uses naturalistic and longitudinal approach of data collection. Participants in the survey were required to use the iPhones provided as their primary mobile phones throughout the period of the study. Factual communication data were collected, passing through the iPhones provided for the assignment, for a period of six months. All data gathered were recorded automatically. The outcome of the survey did not show any significant use of emoticons by the participant. Only $4 \%$ of all messages contained emoticons. Gender differences in terms of usage were captured in the results. The most advantageous aspect of the results was its presentation of the complex nature of genuine computer-mediated communication processes.

The perception of emoticons as conventions was investigated by Garrison et al. (2011). The researchers attempted to examine emoticons as conventions of their own, instead of making comparison with either Standard English (SE), or written and spoken form. The corpus for the study was composed of 59 transcripts that occurred naturally during various IM sessions. These transcripts consisted of about 32,000 words collected by Christina Haas and Pamela Takayoshi for their studies in the year 2005. According to the researchers, the findings of their analyses showed that emoticons are, for the most part, conventionalized attributes as well as paralinguistic elements of IM discourse. They also stated that ever since emoticons are recognized as important semiotic units within a conversational structure, therefore, they should not be approached as "compensatory to language but as contributory to the conversation itself" (Garrison et al., 2011, p. 123).

An investigation was conducted to identify the effects of emoticons on remote communication in a decision 
making gathering. Rivera, Cooke, and Bauhs (1996) sampled twenty three participants to test measures such as conformity, user satisfaction, user frustration, etc. In a motivated session, participants were grouped into two and were to carry out two different assignments that involved a decision making procedure. The first group of twelve members had access to some emoticon buttons, while the remaining eleven did not have. The use of the buttons was discretionary. The results of the exercise showed that participants with emoticons available made use of them out of satisfaction more than those without access to the emoticons at all.

Ip (2002) assessed the effects of emoticons in Instant Messaging (IM) context. She examined to what extent emoticons influence how receivers interpret IM. The findings of the study indicated that both emoticons and punctuation marks are capable of determining how IM users understand messages. Another investigation on newsgroups was conducted by Wolf (2000). Results from the study showed remarkable differences in terms of emoticon use in respect of the two genders. Likewise, Maness's (2008) investigation signified the importance of emoticons in online discourse.

\section{Emoticons as Linguistic Components}

Use of emoticons in CMC interactions represents a sort of shift from verbal to a more or less pictorial representation of meaning. Such linguistic features are codified in a form of pictograms or emoticons to represent, in most cases, gestures, facial expressions, and prosodic elements ever since written electronic language is short of these characteristics (Amaghlobeli, 2012). Pierozak (2003) cites in Amaghlobeli (2012) that there is comparison between graphemes of emoticons and word morphemes. He equally 'underlines the arbitrary relationship between the signifier and signified. The structure of emoticons has been defined as "pictogram-like units formed with alphagrams and topograms of distinctive significative function, and visually conditioned to the referent" (p. 350). As it is the case with other non-verbal elements emoticons are capable of supplementing a verbal context. The attributes of the graphic symbols when used in written form of communication facilitates the flow of semantic properties from the grammatical structure. Uses of emoticons are simply divided into the verbal and non-verbal. It is assumed that "non-verbal emoticons express the para-verbal or non-verbal elements". On the other hand, verbal elements are the "employed graphical pre-designed emoticons. They are animated versions of emoticons that are more sophisticated than the simple combination of keyboard software..." (Amaghlobeli, 2012, pp. 352-353).

Structurally, it is widely known that signs that express meanings through its symbolical resemblance to physical objects are pictograms. That is to say, emoticons could simply be viewed as pictograms combined with graphemes - that is the smallest segment of graphic system recognized over its function in transcribed communication (Anis, 1988). Therefore, according to Anis's (1988) categorization, emoticons are alphabetic graphemes or alphagrams; ponctuo-typographical or topograms; and logogrammatical graphemes or logograms. It is easily noticed that of all these three types, emoticons are mostly composed of alphagrams and topograms, whereby logograms are very uncommon. Graphemes of emoticons are, however, compared to word morphemes. It is also suggested that ever since graphemes of emoticons could be defined as word morphemes, it is also applicable to consider them as lexical morphemes with a complete changed connotation when they are separate (Pierozak, 2003).

Classification wise, most of typographic emoticons are grouped into "emotional-attitudinal emoticons that provide emotional information and represent facial expressions, objects, peoples, animals, action, and appearance". The other group consists of some simple images created by way of keyboard letterings and does not express non-verbal facts. In terms of usage, emoticons are capable of supplementing a verbal situation and also denote importance freely as the case with any other non-verbal mode of communication. For example, in a speech context intonation signifies the proposed meaning more than the way verbal elements do. On the other hand, emoticons can simply change the connotation of a given discourse (Amaghlobeli, 2012, pp. 350-351).

\section{Conclusion}

Related literature reviewed so far has shown that firstly, emoticons have gradually evolved to become part of almost all forms of computer-mediated interactions. Past research studies proposed that CMC lacks non-verbal interaction cues, as a result, Internet users have adopted the use of emoticons to facilitate their communications (Lo, 2008). It is believed to be the substitute for the missing non-verbal cues in written computer-mediated discourse. The literature indicates that emoticons serve as socio-emotional providers in CMC context. Wei (2012) assumes that in the present day the emoticons are not just static depictions of facial expressions nonetheless also graphical and animated representations of various elements.

Secondly, various research works have studied emoticons from different dimensions. In a psychological approach, for example, the focus was on emotion and the role played by emoticons in understanding messages. 
Linguistically, studies have examined emoticons with reference to speaking - writing parameter, semantic and syntactic explanation, functional classification and visual aspects. More than just being paralanguage of the Internet as they were described by Marvin (1995), graphemes of the emoticons were compared to word morphemes with distinctive significative function (Pierozak, 2003). That is to say, they can become morpheme-like units, as the case with word morphemes, there could be a derivation, inflection, or abbreviation, but not unbound. Moreover, a pedagogical investigation has even proposed the working out of an emoticon-based universal language and the possible introduction of such a language into the educational system.

\section{References}

Amaghlobeli, N. (2012). Linguistic features of typographic emoticons in SMS discourse. Theory and Practice in Language Studies, 2(2), 348-354. http://dx.doi.org/10.4304/tpls.2.2.348-354

Anis, J. (1988). L'écriture: théories et déscriptions. Avec la coll. de J.-L. Chiss et C. Puech, Bruxelles: De Boeck Université-Wesmael (coll. « Prisme »).

Argyle, M. (1988). Bodily communication. London: Methuen.

Asteroff, J. F. (1987). Paralanguage in electronic mail: A case study. (Unpublished doctoral dissertation). Columbia University, New York.

Bódi, Z., \& Veszelszki, A. (2006). Emoticons [Emotikonok. Érzelemkifejezés az internetes Kommunikációban]. Magyar Szemiotikai Társaság, Budapest.

Braumann, E., Preveden, O., Saleem, S., Xu, Y., \& Koeszegi, S. T. (2010). The effect of emoticons in synchronous and asynchronous e-negotiations. Proceedings of the $11^{\text {th }}$ Group Decision \& Negotiation Conference (GDN 2010), 113-115. Delft, The Netherlands, University of Nebraska, Omaha.

Bunz, U., \& Campbell, W. S. (2004). Politeness accommodation in electronic mail. Communication Research Reports, 21(1), 11-25. http://dx.doi.org/10.1080/08824090409359963

Constantin, C., Kalyanaraman, S., Stavrositu, C., \& Wagoner, N. (2002, August). To be or not to be emotional: Impression formation effects of emoticons in moderated chatrooms. Paper presented at the Communication Technology and Policy Division at the $85^{\text {th }}$ Annual Convention of the Association for Eduacation in Journalism and Mass Communication (AEJMC), Miami, Florida. Retrieved from http://www.psu.edu/medialab/research/AEJMC.htm

Danesi, M. (2009). Dictionary of media and communications. New York \& London: M. E. Sharpe, Inc.

Danet, B., Ruedenberg-Wright, L., \& Rosenbaum-Tamari, Y. (1997). "HMMM... WHERE'S THAT SMOKE COMING FROM?" Writing, play, and performance on Internet Relay Chat. Journal of Computer-Mediated Communication, 2(4). Retrieved from http://www.ascusc.org/jcmc/vo12/issue4/danet.html

Derks, D., Bos, A. E. R., \& Von Grumbkow, J. (2007). Emoticons and social interaction on the Internet: The importance of social context. Computers in Human Behavior, 23, 842-849. http://dx.doi.org/10.1016/j.chb.2004.11.013

Derks, D., Fischer, A. H., \& Bos, A. E. (2008). The role of emoticon in computer-mediated communication: A review. Computers in Human Behavior, 24, 766-785. http://dx.doi.org/10.1016/j.chb.2007.04.004

Gajadhar, J., \& Green, J. (2005). The importance of nonverbal elements in online chat. Educause Quarterly, 63-64.

Garrison, A., Remley, D., Thomas, P., \& Wierszewski, E. (2011). Conventional faces: Emoticons in instant $\begin{array}{llll}\text { messaging discourse. Computers and } & \text { Composition, } 28,125 .\end{array}$ http://dx.doi.org/10.1016/j.compcom.2011.04.001

Godin, S. (1993). The smiley dictionary. Berkeley, CA: Peachpit.

Herring, S. (2001). Computer-mediated discourse. In D. Schiffrin, D. Tannen, \& H. Hamilton (Eds.), The handbook of discourse analysis (pp. 612-634). Oxford: Blackwell Publishers.

Huang, A. H., Yen, D. C., \& Zhang, X. (2008). Exploring the potential effects of emoticons. Information \& Management, 45, 466-473. http://dx.doi.org/10.1016/j.im.2008.07.001

Innocent, T. (2001). The language of iconica. Leonardo, 34(3), 255. http://dx.doi.org/10.1162/002409401750287038

Ip, A. (2002). The impact of emoticons on affect interpretation in Instant Messaging. Retrieved from $\mathrm{http}: / /$ amysmile.com/pastprj/emoticon_paper.pdf 
Lang, P. (2009). Electronic emotion: The mediation of emotion via information and communication technologies. In J. Vincent, \& L. Fortunati (Eds.), Interdisciplinary Communication Studies (pp. 237).

Lo, S. K. (2008). The nonverbal communication functions of emoticons in computer-mediated communication. Cyberpsychology \& Behavior, 11(5), 595-597. http://dx.doi.org/10.1089/cpb.2007.0132

Luor, T., Lu, H. P., Wu, L. L., \& Tao, Y. H. (2010). The effect of emoticon in simplex and complex task-oriented communication: An empirical study of Instant Messaging. Computers in Human Behavior, 26(5), 889-895. http://dx.doi.org/10.1016/j.chb.2010.02.003

Maness, J. M. (2008). A linguistic analysis of chat reference conversation with 18-24 year old college students. The Journal of Academic Librarianship, 34(1), 31-38. http://dx.doi.org/10.1016/j.acalib.2007.11.008

Marvin, L. E. (1995). Spoof, spam, lurk and lag: The aesthetics of text-based virtual realities. Journal of Computer-Mediated Communication, 1(2). Retrieved from http://jcmc.indiana.edu/vol1/issue2/marvin.html

Mitchell, A. A. (1986). The effect of verbal and visual components of advertisements on brand attitudes and attitude toward the ad. Journal of Consumer Research, 13, 12-24. http://dx.doi.org/10.1086/209044

Parkinson, M. (2007). Do-it-yourself: Billion dollar business graphics. Virginia, VA: Pepperlip Inc.

Pierozak, I. (2003). Le français tchaté : une étude en trois dimensions - sociolinguistique, syntaxique et graphique - $d \_$usages IRC. Doctoral dissertation, Université d_Aix- Marseille I.

Raymond, E. S. (1994). The new Hacker's dictionary. Cambridge: The MIT Press.

Rezabek, L. L., \& Cochenour, J. J. (1998). Visual cues in computer-mediated communication: Supplementing text with emoticons. Journal of Visual Literacy, 18, 201-215.

Riva, G. (2002). The sociocognitive psychology of computer-mediated communication: The present and future of technology-based interactions. CyberPsychology \& Behavior, 5, 581-598. http://dx.doi.org/10.1089/109493102321018222

Rivera, K., Cooke, N. J., \& Bauhs, J. A. (1996). The effects of emotional icons on remote communication. CHI 96 Interactive Posters, 99-100. http://dx.doi.org/10.1145/257089.257180

Sanderson, D. (1993). Smileys. Sebastopol, CA: O’Reilly.

Sproull, L., \& Kiesler, S. (1986). Reducing social context cues: Electronic mail in organizational communication. Management Sciences, 32, 1492-1512. http://dx.doi.org/10.1287/mnsc.32.11.1492

Taiwo, R. (2010). 'The thumb tribe': Creativity and social change through SMS in Nigeria. California Linguistic Notes, $X X X V(1)$.

Thompson, P. A., \& Foulger, D. A. (1996). Effects of pictographs and quoting on flaming in electronic mail. Computers in Human Behavior, 12, 225-243. http://dx.doi.org/10.1016/0747-5632(96)00004-0

Tossell, C. C., Kortum, P., Shepard, C., Barg-Walkow, L. H., \& Rahmati, A. (2012). A longitudinal study of emoticon use in text messaging from smart phones. Computers in Human Behavior, 28, 659-663. http://dx.doi.org/10.1016/j.chb.2011.11.012

Walther, J. B. (1992). Interpersonal effects in computer-mediated interaction. Communication Research, 19, 52-90. http://dx.doi.org/10.1177/009365092019001003

Walther, P. J., \& D'Addario, P. K. (2001). The impacts of emoticons on message interpretation in computer-mediated communication. Social Science Computer Review, 19(3), 324-347. http://dx.doi.org/10.1177/089443930101900307

Wei, A. C. Y. (2012). Emoticons and the non-verbal communication: With reference to Facebook (Unpublished master's thesis). Department of Media Studies, Christ University, Bangalore - India.

Wolf, A. (2000). Emotional expression online: Gender differences in emoticon use. CyberPsychology \& Behavior, 3(5), 827-833. http://dx.doi.org/10.1089/10949310050191809 